\title{
Performance Research on Hybrid System Using MATLAB Simulink
}

\author{
Kamal Bhatia, Sanjay Nayak, Maneesh Kumar
}

\begin{abstract}
This paper proposes the performance analysis of hybrid system using MATLAB simulation. In the present era, the increasing energy demand due to increase in the large number of loads depress the electrical grid system to fulfil the energy demand of each and every customer. It is impossible for the grid system to do so, therefore to get rid off from these issues a renewable energy-based hybrid system is developed that fulfils the energy demand in most efficient way without undergoing in the process of load shedding. The system is design in the MATLAB Simulink and the result obtained is compared to improve the efficiency of the system.
\end{abstract}

Keywords- electrical grid system, hybrid system, solar energy, wind energy, load shedding.

\section{INTRODUCTION}

The resources of the conventional energy sources such as the oil, gas and coal are depleting with the faster rate [1]. These fossil fuels are very costly as their extinction rate is very fast. The world is replacing these fossil fuels from the renewable energy resources as these fossil fuel causes high amount of air pollution, water pollution and noise pollution [2]. The use of conventional energy resources not only affects the ecological balance but also affects the aquatic life of fishes living in water by promoting global warming [3]. Hence, due to these reasons the people living in the modern world decided to use renewable energy resources in place of conventional energy resources. The renewable energy resources help in making the environment neat and clean [4]. The use of non-conventional energy resources also promotes the use of green energy. In present, there exist many such renewable energy sources like biogas, solar, wind and tidal. Among all the renewable energy sources the solar energy and wind energy are found in abundant in almost all the countries of the world [5] .

The main advantage of such types of renewable energy resources as compared to other types of renewable energy resources are that they are pollution free, does not make any noise during operation, does not affects the life of human being and aquatic animals and it is free occurring source provided by nature. The earth accepts the sun rays with variable light intensity in a day. If a solar PV module is

Revised Version Manuscript Received on 10 September, 2019.

Kamal Bhatia, Department of Electronics \& Communication Engineering, Noida Institute of Engineering and Technology, UttarPradesh, India.

(Email: researchnietip@gmail.com)

Sanjay Nayak, Department of Electronics \& Communication Engineering, Noida Institute of Engineering and Technology, UttarPradesh, India.

(Email: researchnietip@gmail.com)

Maneesh Kumar, Department of Computer Science \& Engineering, Noida Institute of Engineering and Technology, UttarPradesh, India.

(Email: researchnietip@gmail.com) installed on the roof top of any building then the sun light can be captured through this module and converts the light energy into electrical energy directly [6]. The earth also receives the abundant of wind energy in many different parts of the world. For harnessing such wind energy, a wind turbine is made that converts the high and low pressure of wind into electrical energy.

With the rapid increase in demand of energy due to the increasing of load, it is very difficult for the electrical grid to fulfil the energy demand. For supplying the power and to avoid the failure of grid, the grid system does the load shedding and fulfils the energy demand. But this process is obvious and fails to fulfil the energy demand of each and every customer [7]. Therefore, this paper proposes a combine method of generating electricity by utilizing the solar energy and wind energy simultaneously and analysing the characteristics of such hybrid system by using the MATLAB Simulink software. By doing so, the electrical grid system will be free from the stress of fulfilling the energy demand by performing the load shedding. This hybrid system is connected with the electrical grid near the load to fulfil the load demand by supplying the power from the electrical grid to the load [8].

\section{SOLAR PHOTOVOLTAIC MODULE}

A solar photovoltaic module is a combination of solar PV cell connected in series of the solar panel. The solar PV module works on the principle of photovoltaic effect [9]. According to the photovoltaic effect when the sun lights falls on the plate of solar panel which is made up on p-n junction, the metal plates absorb heat of solar light and gets energised. After getting energizing the electron and holes are generated. The generated electrons start flowing towards $n$ type semiconductor and generated holes start flowing towards $p$ type semiconductor. By this process the current start flowing from positive terminal to negative terminal of the panel.

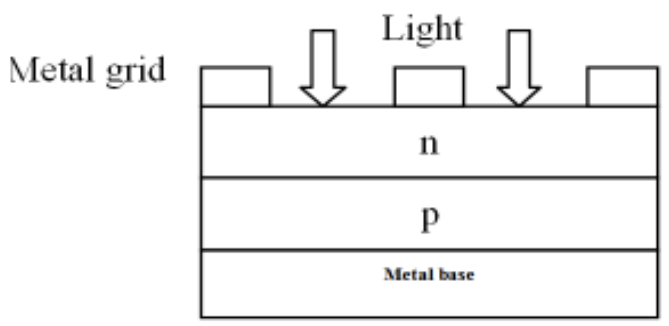

Fig. 1: Structure of PV cell

Published By:

Blue Eyes Intelligence Engineering

\& Sciences Publication 
The solar array is basically the combination of large number of solar cells. The structure of PV cell is shown in fig.1. These cells on combination made a solar PV module and this solar module is sufficient to provide a supply to multiple number of households. For capturing maximum dc power from the solar module, a maximum power point tracking (MPPT) controller is connected with the panel. The $\mathrm{dc}-\mathrm{dc}$ converter is also connected to the MPPT controller for converting fluctuating dc voltages into constant dc voltages. An inverting unit is coupled with the dc-dc converter for converting constant dc voltage into ac voltage. Further the ac power is transmitted to the loads through the electrical grid for fulfilling the energy demand. Fig.2 represents the schematic diagrams of solar photovoltaic (PV) module.

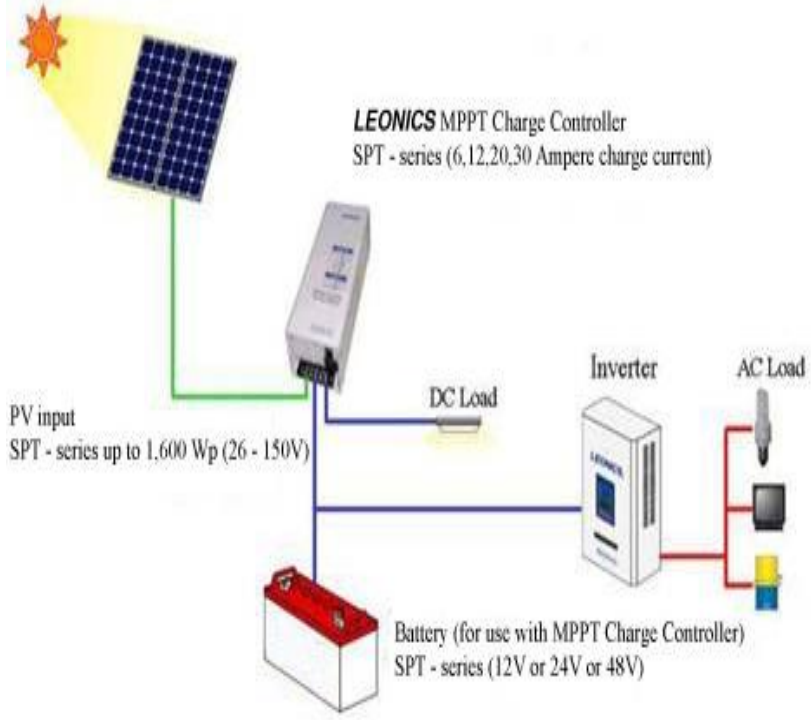

Fig.2 Schematic representation of Solar PV module

\section{WIND ENERGY CONVERSION SYSTEM}

Wind energy is naturally occurring energy form due to the pressure difference between land surface and atmosphere. Hence, the wind energy can be successfully utilized to convert into electrical energy by the use of wind turbine [10]. The wind turbine is nothing but a combination of blades connected on the shaft of induction generator. For capturing high amount of wind energy, the height of the blades must be very high. The generated electricity can be converted into dc through the rectifying unit and the dc current is stored in the battery for further utilization.

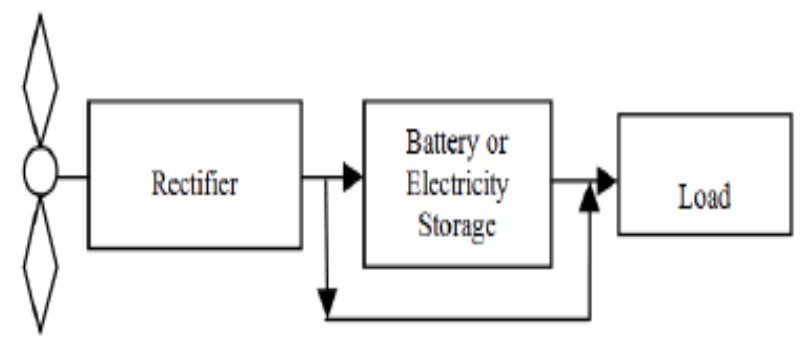

Fig. 3: Block diagram of windmill power system

The block diagram of wind power turbine is shown by fig.3. It comprises of a couple of blades for harnessing wind energy, an induction generator for converting wind energy into electrical energy, a rectifier for converting ac voltage into dc voltage and a battery for storing the converted dc current. It is to be noted that the generated electrical power by induction generated can be directly used by the ac loads. Here rectifier is used to store the power for further utilization.

\section{HYBRID GRID CONNECTED SYSTEM}

For generating an electrical power for fulfilling the requirement of energy demand of customers by using the renewable energy resources, a hybrid system is connected to the electrical grid. Hybrid system comprises of a solar PV module and wind power plant that generates electrical energy simultaneously and stores into the battery.

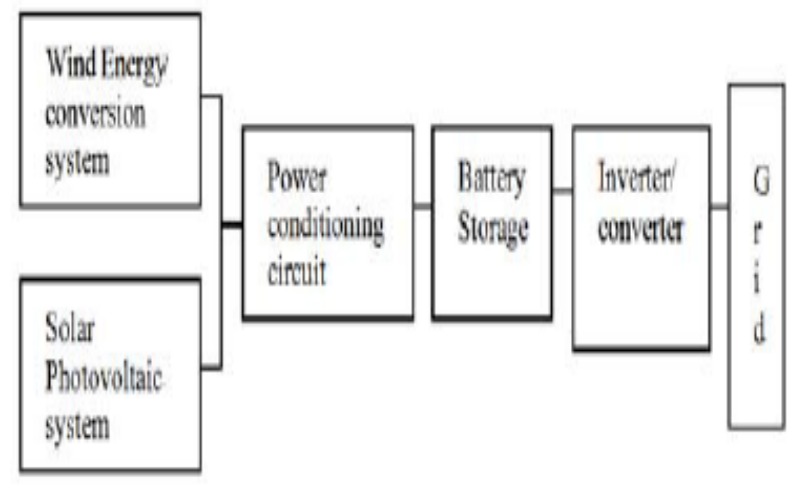

\section{Fig. 4: Block diagram of lỵbrid WindPYssystem}

Fig.4 shows the block diagram of hybrid grid connected system. The hybrid system includes the wind energy conversion system and solar photovoltaic panel for generating electrical energy by extracting wind energy and solar energy resources. The above block diagram consists of the power conditioning circuit for converting ac power into $\mathrm{dc}$ power, a battery storage unit coupled with the power conditioning circuit for storing the converted dc power. The dc load can be directly connected to the battery for providing power to the dc equipment. After storing dc power in the battery, it is further transferred to the inverting unit for converting dc power into ac power. The ac power is further supplied to the electrical grid for transmitting ac power and supporting the grid for fulfilling the peak load demand.

\section{SIMULATION MODEL AND RESULT}

The wind turbine and solar PV module is connected to the electrical grid system and acting as a secondary source for suppling electrical power from grid station to the load. The wind turbine generates alternating ac power therefore, to convert this alternating power into dc power a rectifier is coupled with the induction generator to convert ac voltage into dc voltage and a battery is connected to the rectifier to store dc output power.

Second is the solar panel that generates electricity by converting solar energy into electrical energy and acting as a secondary source for providing electricity to the households via electrical grid station. The solar panel generates dc power 
which is directly stored into the battery by converting variable dc power into stable dc power through a dc-dc converter. After storing the total combined power from the hybrid system, the power is further transferred to the region where there is a peak demand. The complete model of hybrid connected grid system is shown in fig.5. This model is drawn with the help of MATLAB Simulink software.

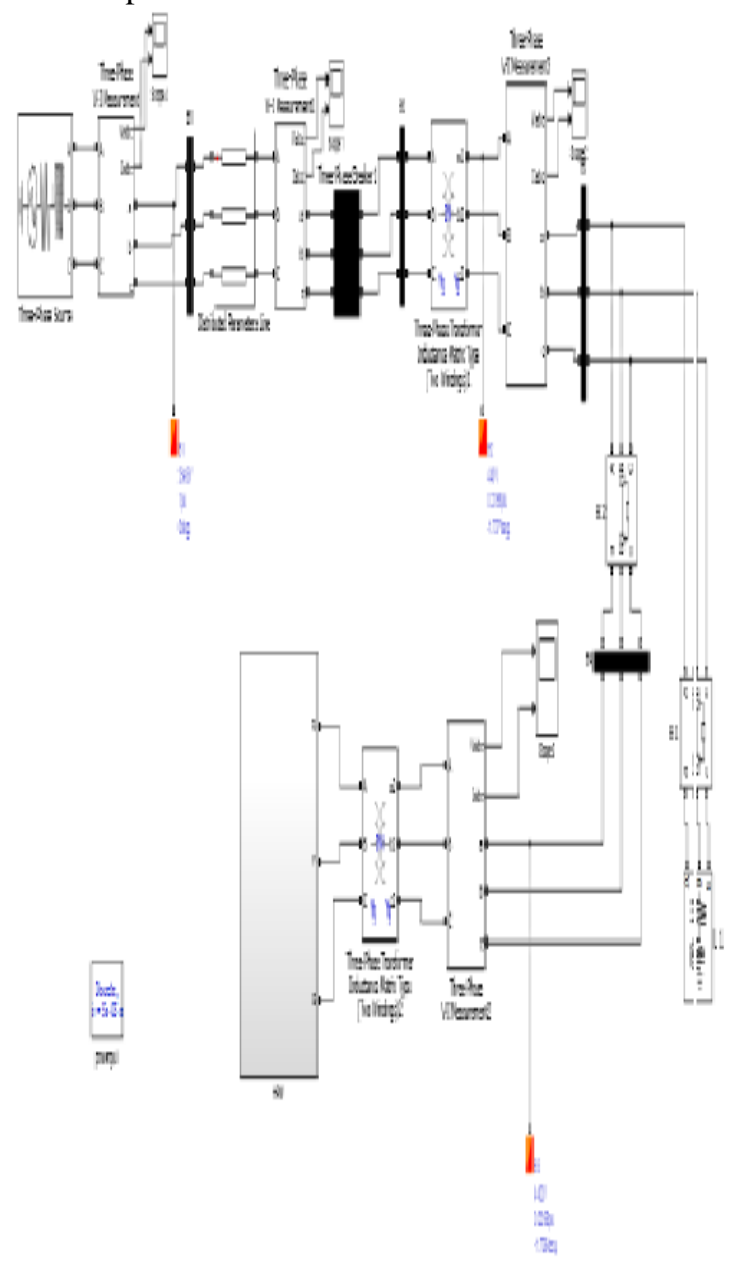

\section{Fig. 5 : Complete model of grid connected hybrid system}

After simulation the output waveform of wind turbine is shown in fig.6. and the fluctuated output waveform of solar and wind hybrid system is shown by fig.7. After compensation and connecting whole of the hybrid system with the grid, the regulated output waveform is achieved which is shown by fig. 8 .

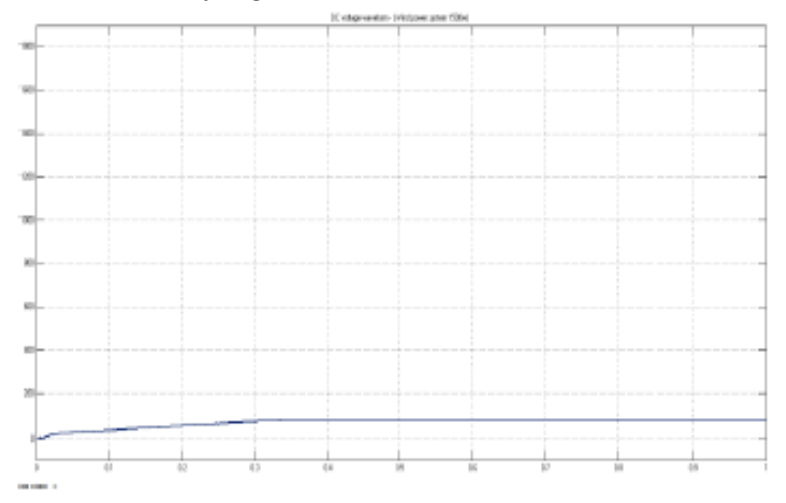

Fig. 6: Output of wind turbine
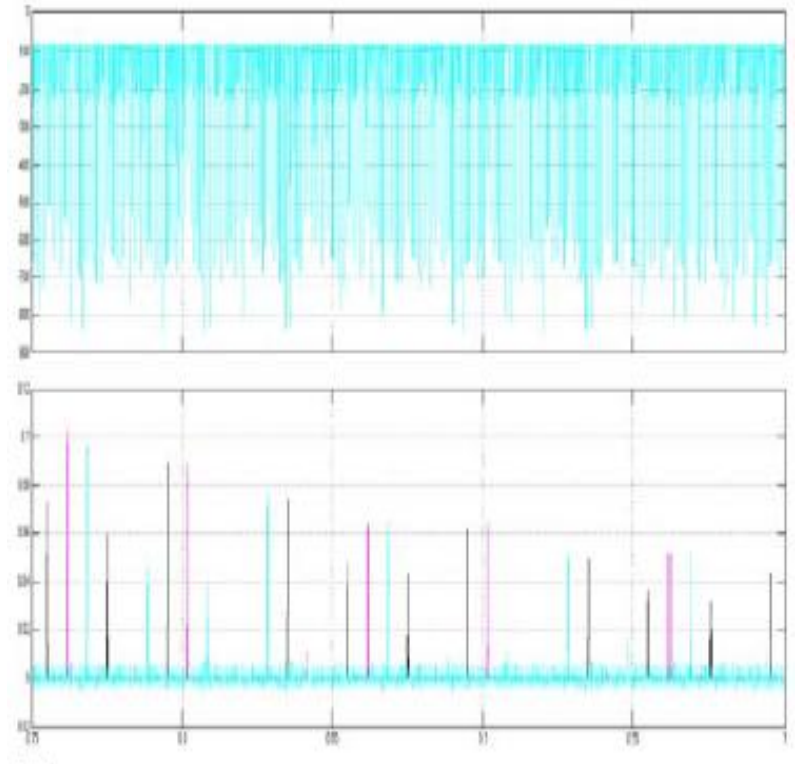

Fig. 7: Irregular Output of wind and hybrid system

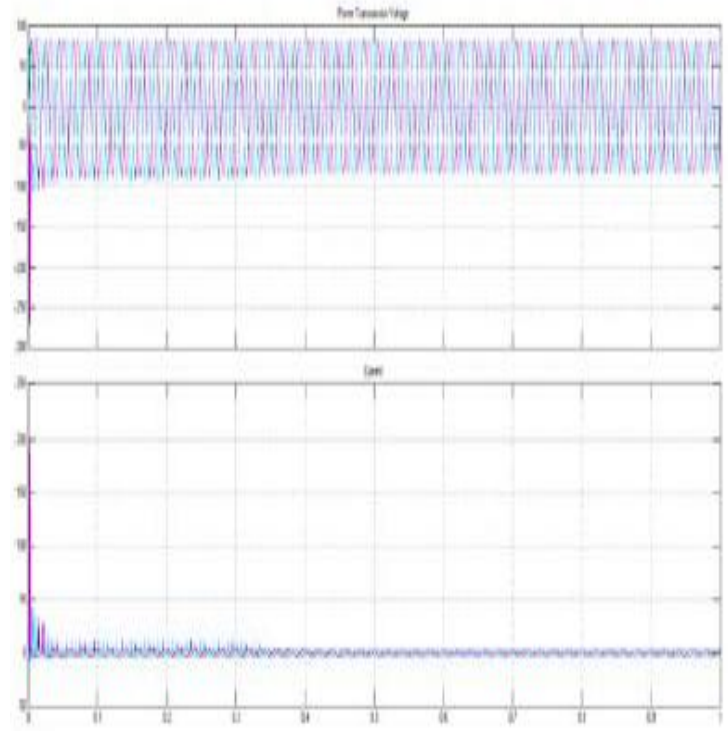

Fig, 9: Complete model output shoring a regulated roltage and current supplied to the gird

\section{CONCLUSION}

The performance characteristics of the hybrid connected system is tested through the MATLAB simulation and the output waveform of hybrid system gets improved by developing proposed simulation model. In the grid connected power system there is always a power quality issue due to the overloading condition. For a large number of connected loads, it is impossible for the electrical grid to supply the continuous power. So conventionally, it performs a load shedding to fulfil the energy demand. Hence, by employing the proposed and improved hybrid solar and wind system it becomes very easy task for the grid station to supply electric power continuously without suffering from load shedding problems.

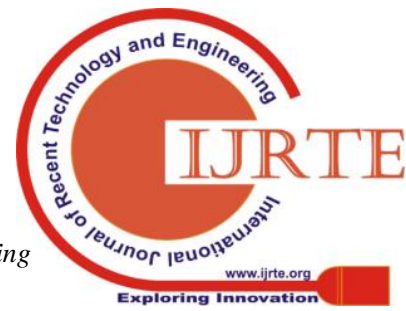




\section{REFERENCES}

1. S. Shafiee and E. Topal, "When will fossil fuel reserves be diminished?," Energy Policy, 2009.

2. A. F. Armor, R. D. Srivastava, H. G. Mcllvried, T. D. Marshall, and S. I. Plasynski, "Fossil fuels," in Energy Efficiency and Renewable Energy: Handbook, Second Edition, 2015

3. M. Höök and X. Tang, "Depletion of fossil fuels and anthropogenic climate change-A review," Energy Policy, 2013.

4. A. Demirbaş, "Global renewable energy resources," Energy Sources, Part A Recover. Util. Environ. Eff., 2006.

5. S. Sumathi, L. Ashok Kumar, and P. Surekha, Solar PV and Wind Energy Conversion Systems. 2015.

6. M. R. Patel, Wind and Solar Power Systems. 2005.

7. S. Ould Amrouche, D. Rekioua, T. Rekioua, and S. Bacha, "Overview of energy storage in renewable energy systems," Int. J. Hydrogen Energy, 2016.

8. M. Abdelaziz Mohamed and A. M. Eltamaly, "Modeling of hybrid renewable energy system," in Studies in Systems, Decision and Control, 2018.

9. G. K. Singh, "Solar power generation by PV (photovoltaic) technology: A review," Energy. 2013.

10. J. F. Manwell, J. G. McGowan, and A. L. Rogers, Wind Energy Explained: Theory, Design and Application. 2010. 